\title{
CONFLITOS EMPRESARIAIS: A COMISSÃO DE VALORES MOBILIÁRIOS (CVM) E SEUS MEIOS DE ADMINISTRAÇÃO DE CONFLITOS
}

\section{${ }^{1}$ Wagner De Mello Brito \\ 2 Daniela De Oliveira Duque-estrada De La Peña}

\begin{abstract}
RESUMO
No presente artigo, busco apresentar conclusões parciais e explicitar argumentos obtidos em observação participante, acerca dos meios de administração de conflitos e as representações dos agentes da CVM com atuação no Rio de Janeiro, no que concerne ao dever legal dos administradores das Sociedades Anônimas de capital aberto em informar aos investidores do mercado de capitais a existência de fatos relevantes, internos à companhia, que possam influir no processo de decisão dos investidores em agregar, manter ou retirar capital em determinada empresa. Busco analisar um ethos institucional voltado à proteção do ente abstrato mercado em detrimento da figura do investidor.
\end{abstract}

Palavras-chave: Mercado, Capitais, CVM, Investidor

\section{CONFLICTO DE NEGOCIO: LA COMISIÓN DE VALORES (CVM) Y SU MEDIOS DE GESTIÓN DE CONFLICTOS}

\section{RESUMEN}

En este artículo se pretende presentar los resultados parciales y argumentos explícitos obtenidos en la observación participante, unos medios de gestión de conflictos y las representaciones de los agentes de la CVM que operan en Río de Janeiro. Trato de analizar la obligación de los directores de la Corporación Abierto a informar a los inversores la existencia de hechos materiales, que pueden influir en la toma de decisiones de los inversionistas en mantener o retirar capital en una empresa determinada. Trato de analizar un ethos institucional destinada a proteger a lo "mercado" abstracto en detrimento de la figura del inversor.

Palabras-claves: Mercado, Capital, CVM, Inversor

\footnotetext{
1 Doutor em Direito pela Universidade Gama Filho, Rio de Janeiro. (Brasil). Professor da Universidade Estácio de Sá, Rio de Janeiro. (Brasil). E-mail: wmbrito@gmail.com

2 Doutoranda em Direito pela Universidade Veiga de Almeida - PPGD/UVA, Rio de Janeiro. (Brasil). Coordenadora do Curso de Pós-Graduação Lato Sensu da Universidade Estácio de Sá, Rio de Janeiro. (Brasil). E-mail: prof.danieladuque@terra.com.br
} 


\section{INTRODUÇÃO}

O desenvolvimento econômico sustentável no Brasil depende de vultosos investimentos de recursos financeiros e capacitação humana, necessários à expansão contínua da capacidade produtiva de bens de consumo em quantidade acessível à população, segundo estudos realizados nos últimos anos (Fraga; Goldfajn e Minella2004). Este desenvolvimento permite a criação de ofertas de empregos e a melhora do perfil de distribuição de renda.

Desde o pós-guerra, os ciclos de desenvolvimento na economia brasileira foram caracterizados pela intervenção do Estado na economia (LAZZARINI, 2011).

Nelson Eizirik (EIZIRIK, 2011) afirma que desde a crise dos anos 80, a combinação do capital estrangeiro com recursos oriundos das instituições financeiras públicas tem sido insuficientes para o nosso desenvolvimento econômico sustentável. Assim, o mercado de capitais surge como alternativa às limitações de acesso a financiamento público aos empresários.

Dentre as instituições que atuam nesse mercado, a constituição de Sociedade Anônima viabiliza o aporte de vultosos investimentos privados para a realização de grandes empreendimentos. Trata-se de único tipo societário que pode adotar a forma aberta desde que obtenha autorização da CVM para negociar publicamente seus valores mobiliários em bolsa de valores. A CVM é uma autarquia federal, cuja função institucional é a de fiscalizar ${ }^{1}$ a atuação da companhia aberta ${ }^{2}$ no mercado de capitais.

As companhias abertas, por seu modo de atuação e pela maneira como se dá o investimento de cada acionista (investidor), permite a distribuição de seus lucros aos seus investidores, já que, em geral, seus papéis, também conhecidos como valores mobiliários, são negociados em bolsa de valores, independentemente dos atributos pessoais de cada acionista.

\footnotetext{
${ }^{1}$ Lei 6385/76. Art. $5^{\text {o }}$ É instituída a Comissão de Valores Mobiliários, entidade autárquica em regime especial, vinculada ao Ministério da Fazenda, com personalidade jurídica e patrimônio próprios, dotada de autoridade administrativa independente, ausência de subordinação hierárquica, mandato fixo e estabilidade de seus dirigentes, e autonomia financeira e orçamentária; Art. 16. Depende de prévia autorização da Comissão de Valores Mobiliários o exercício das seguintes atividades: I - distribuição de emissão no mercado (Art. 15, I); II compra de valores mobiliários para revendê-los por conta própria (Art. 15, II); III - mediação ou corretagem de operações com valores mobiliários; e IV - compensação e liquidação de operações com valores mobiliários. Parágrafo único. Só os agentes autônomos e as sociedades com registro na Comissão poderão exercer a atividade de mediação ou corretagem de valores mobiliários fora da bolsa.
}

${ }^{2}$ Lei 6385/76: Art. 22. Considera-se aberta a companhia cujos valores mobiliários estejam admitidos à negociação na bolsa ou no mercado de balcão. 
Em razão dessas características formou-se um mercado de ações no Brasil que está diretamente ligado aos resultados obtidos pela empresa em suas atividades. É o chamado mercado de capital ou mercado mobiliário.

A CVM visa, entre outras atribuições, proteger os titulares de valores mobiliários contra emissões irregulares de papeis, bem como impedir a prática de atos ilegais de administradores e acionistas controladores de companhias, inibindo fraudes ou manipulações destinadas a criar condições artificiais de demanda, oferta ou preço de valores mobiliários negociados no mercado, conforme disciplina da lei $\mathrm{n}^{\circ}$. 6.385/76.

Por fim, à CVM também cabe a atribuição de assegurar o acesso do público a informações relevantes acerca de valores mobiliários negociados, relativas às companhias que os tenham emitido, bem como assegurar a observância de práticas comerciais equitativas no mercado de valores mobiliários.

Neste artigo, procuramos destacar, dentre as várias atribuições da CVM, a função de fiscalizar a divulgação de fatos relevantes pelos administradores das companhias abertas. Este dever ${ }^{3}$ de divulgação figura entre os assuntos mais atuais e polêmicos do direito empresarial e econômico brasileiro, porque se considera relevante qualquer fato que possa influir, de modo ponderável, na decisão dos investidores do mercado. Este assunto ganhou notoriedade recentemente em razão da ampla divulgação pela imprensa das investigações relativas à suposta violação desta obrigação por administradores da OGX. O dever de divulgar os fatos relevantes constitui, neste campo, uma proteção para os investidores na medida em que devem ser prestadas todas as informações relevantes para a tomada de decisão sobre seus investimentos a respeito das companhias que possuem títulos publicamente negociados. $\mathrm{O}$ objetivo é garantir que todos os dados importantes para o processo de precificação dos valores mobiliários de uma companhia aberta sejam disponibilizados de forma ampla, simultânea e equitativa a todos os agentes de mercado, contribuindo para o eficiente funcionamento do mercado de capitais.

\footnotetext{
${ }^{3}$ Art. 157. O administrador de companhia aberta deve declarar, ao firmar o termo de posse, o número de ações, bônus de subscrição, opções de compra de ações e debêntures conversíveis em ações, de emissão da companhia e de sociedades controladas ou do mesmo grupo, de que seja titular.; $\$ 4^{\circ}$ Os administradores da companhia aberta são obrigados a comunicar imediatamente à bolsa de valores e a divulgar pela imprensa qualquer deliberação da assembleia-geral ou dos órgãos de administração da companhia, ou fato relevante ocorrido nos seus negócios, que possa influir, de modo ponderável, na decisão dos investidores do mercado de vender ou comprar valores mobiliários emitidos pela companhia.
} 
Ao longo dos anos, vem se tornando possível identificar situações econômicas potencialmente relevantes que, no entanto, são omitidas por administradores de companhias abertas e que se tornam, por isso mesmo, objeto de julgamento em Processo Administrativo Sancionador (PAS) na CVM. Podem ser citados, como exemplos, os casos de reorganizações societárias, aquisição de controle, a existência de processos judiciais, incluindo pedidos de falência, recuperação judicial ou extrajudicial, assim como contratos relevantes em geral, empréstimos e renegociações de dívidas (BOECHEM e PINTO RIOS, 2014).

Assim, podemos destacar que a contratação de empréstimos, embora seja geralmente um ato rotineiro para as companhias, pode caracterizar um fato relevante quando envolver a renegociação de dívidas, a celebração ou a extinção de contrato ou o insucesso no seu cumprimento, principalmente quando a expectativa de concretização for de conhecimento público. A determinação da relevância de um empréstimo envolve análise sobre a sua importância econômica para a companhia que é baseada em critérios subjetivos de quem detém, na CVM, o poder de tal avaliação. Bons exemplos dessas subjetividades podem ser observados no PAS RJ 2006/4476 e PAS RJ 2007/1079, nos quais, a CVM analisou dois empréstimos da CAEMI - Caemi Mineração e Metalurgia S.A. - para sua controladora, à Companhia Vale do Rio Doce, no valor total de US\$ 400 milhões. Na primeira decisão o empréstimo foi considerado relevante porque representava 38,07\% do patrimônio líquido da CAEMI. Já a segunda decisão, não o considerou relevante porque representava 3,42\% do patrimônio líquido da Vale. Assim, valendo-se de um mesmo critério - valor do patrimônio líquido - a CVM concluiu de forma diferente acerca da existência de relevância do fato.

Além da importância econômica em termos quantitativos, outra questão interessante investigada refere-se à relevância qualitativa dos empréstimos, especialmente em operações celebradas entre partes que desfrutam de algum tratamento privilegiado. Isto acontece, por exemplo, quando é concedida ao acionista controlador a possibilidade de obtenção de empréstimo abaixo do seu custo de captação. Este tratamento representa a ideia de "rede corporativa" ou "mundo pequeno", categoria que aponta para o favorecimento de informações privilegiadas acessíveis a uma rede de pessoas unidas por laços familiares ou conexões pessoais (KOGUT e WALKER, 2001).

Assim, o presente artigo tem por objetivo apresentar conclusões, ainda que parciais, que contribuam para a construção de conhecimento sobre os problemas e necessidades relacionadas aos métodos de resolução dos conflitos existentes nos meios empresariais e julgados na CVM no Estado do Rio de Janeiro. Devemos destacar que a CVM tem atribuição de identificar e até punir ${ }^{4}$ comportamentos considerados criminosos e que possam ser julgados em definitivo pelo Judiciário. 


\section{OBJETIVOS}

Este artigo objetiva contribuir para a construção e consolidação das pesquisas científicas nas áreas jurídica e econômica articuladas às ciências sociais, visando aprofundar o conhecimento sobre o efetivo funcionamento do mercado de capitais brasileiro como uma de suas instituições econômicas e financeiras. Assim, busca-se contribuir para o incentivo ao debate entre pesquisadores por meio da divulgação de pesquisa empírica na capital do Rio de Janeiro.

Do mesmo modo, o artigo pretende analisar também o grau de amadurecimento do mercado de capitais no Estado do Rio de Janeiro, para explicitar valores e atitudes que contribuam para conhecer e compreender as práticas que interfiram na transparência do próprio mercado. Pretende-se, assim promover a articulação dos saberes legais, doutrinários do direito brasileiro, dotados de abstração e articulados com as práticas dos agentes envolvidos nos diversos espaços de resolução de conflitos empresariais. Tal articulação terá por fim criar conteúdo científico demonstrável, passível de intercambio que agregue conhecimento novo ao trabalho de outros pesquisadores.

\section{METODOLOGIA}

O presente artigo é resultado de um programa de Pesquisa e Extensão na modalidade de Pesquisa Produtividade iniciado desde fevereiro de 2015 no seio do curso de Direito da Universidade Estácio de Sá, Rio de Janeiro, Brasil. A pesquisa foi realizada com incentivo inanceiro e acadêmico da Universidade Estácio de Sá, dentro do programa de pesquisa produtividade, na qual, honrosamente faço parte.

$\mathrm{O}$ artigo reflete conclusões parciais de pesquisa qualitativa e quantitativa, com inspiração etnográfica realizada no âmbito das instalações da Comissão de Valores Mobiliários (CVM) sediada na capital do Rio de Janeiro, cujos departamentos, números de processos e pessoas observadas serão mantidos em sigilo como é a praxe em pesquisas feitas no âmbito das ciências sociais.

\footnotetext{
${ }^{4}$ Lei 6385/76 - Art. $9^{\circ}$ A Comissão de Valores Mobiliários, observado o disposto no $\$ 2$ o do art. 15, poderá: V apurar, mediante processo administrativo, atos ilegais e práticas não equitativas de administradores, membros do conselho fiscal e acionistas de companhias abertas, dos intermediários e dos demais participantes do mercado; $\$$ $2 o$ O processo, nos casos do inciso $V$ deste artigo, poderá ser precedido de etapa investigativa, em que será assegurado o sigilo necessário à lucidação dos fatos ou exigido pelo interesse público, e observará o procedimento fixado pela Comissão. §6o A Comissão será competente para apurar e punir condutas fraudulentas no mercado de valores mobiliários sempre que: I - seus efeitos ocasionem danos a pessoas residentes no território nacional, independentemente do local em que tenham ocorrido; e II - os atos ou omissões relevantes tenham sido praticados em território nacional.
} 
Considerando que a pesquisa se deu prioritariamente com inspiração etnográfica, foi adotado o método de observação participante dentro das instalações da CVM a fim de se tentar compreender como são processados, e com qual velocidade, os fatos relevantes ocorridos no seio das Sociedades Anônimas de Capital Aberto com atuação no Brasil.

Inicialmente a observação foi realizada no âmbito do órgão colegiado da CVM onde se realizam os julgamentos e se imputam punições aos acionistas que deixam de prestar informação relevante ao mercado. Após tais investigações, foram feitas também observações e análises no âmbito da ampliadas as atividades de observação participante na biblioteca e no departamento de investigação à atuação dos agentes econômicos, ambos da Comissão de Valores Mobiliários (CVM).

As conclusões deste artigo são resultantes parciais da pesquisa que se iniciou no ano de 2015, na cidade do Rio de Janeiro e que ainda está sendo realizada, face à dificuldade de acesso a todos os órgãos da Comissão de Valores Mobiliários (CVM) na capital do Rio de Janeiro. Foram analisados cerca de 100 (cem) Processos Administrativos Sancionadores (PAS), findos ou ainda em curso no âmbito da CVM. Embora os estudos sobre a CVM seja abundante no campo e no curso de Direito, mais especificamente, no âmbito do direito empresarial, o presente artigo não tem por escopo reproduzir os aspectos normativos ou dogmáticos da legislação, jurisprudência e doutrinas aplicáveis à matéria, mas sim e principalmente, analisar a forma com que são administrados os Processos Administrativos Sancionadores (PAS) na Comissão de Valores Mobiliários (CVM).

Uma análise que leve em conta aspectos da formação e do desenvolvimento da sociedade brasileira e do seu direito, e que pretenda a análise empírica do seu objeto, requer métodos que hoje são utilizados mais cotidianamente nas ciências sociais.

Este artigo, em um primeiro momento, busca refletir acerca dos diferentes problemas relativos a os conflitos existentes entre os investidores do mercado de capitais e as companhias de capital aberto que, eventualmente são levadas à solução pela Comissão de Valores Mobiliários (CVM) Diante desta perspectiva, entendeu-se que seria necessário recorrer à pesquisa qualitativa e quantitativa.

Sendo assim, a investigação foi realizada por meio de multimétodos (NIELSEN, 2010) ${ }^{5}$, tais como: observação direta; observação participante; entrevistas abertas; análise de documentos legais; doutrinários e jurisprudenciais; grupos focais, entre outros. Assim, foram utilizadas metodologias que priorizam o tratamento qualitativo dos dados, sem afastar eventuais análises de bases quantitativas advindas das movimentações do mercado. Buscouse, assim, a produção e análise de dados empiricamente obtidos. 
Em um primeiro momento foi realizado o levantamento bibliográfico sobre o tema em sites eletrônicos oficiais brasileiros e em bibliotecas, especialmente no sitio da Comissão de Valores Mobiliários $(\mathrm{CVM})^{6}$. Compõe ainda essa análise o exame dos documentos relativos aos processos de administração de conflitos do mercado de capitais, conhecidos como Processos Administrativos Sancionadores (PAS).

Em seguida, buscamos levantar as representações, percepções, opiniões e experiências dos diversos atores envolvidos no mercado de capital. Assim, fizemos contato com investidores; pessoas físicas e representantes de pessoas jurídicas; funcionários da CVM; com acesso a fatos direta ou indiretamente relacionados a crimes econômico-financeiros. Assim, procuramos ter acesso em maior tempo possível, a todos aqueles que poderiam manifestar distintos pontos de vistas acerca da segurança, da transparência e da confiabilidade do mercado de capitais acessível e submetido à CVM com sede no Rio de Janeiro. Para tais fins, privilegia-se a observação participante (MALINOWSKI, 1922: 1-25), consistente na realização de trabalho de campo, entrevistas abertas e a descrição com inspiração etnográfica.

A pesquisa ainda está em curso e ainda estão sendo observadas as rotinas comportamentais dos investidores e os conteúdos das informações franqueadas por estes atores à CVM, bem como os aspectos regimentais e legais dessa atuação. Entretanto, apresentamos neste artigo algumas considerações acerca dos mecanismos utilizados pelas companhias de capital aberto, suas estratégias de controle da transparência das informações e seus respectivos conflitos empresariais e meios de resolução utilizados pela Comissão de Valores Mobiliários (CVM).

\section{A COMISSÃO DE VALORES MOBILIÁRIOS (CVM)}

Em determinados países com formas e instituições de organização econômica menos complexas, a possibilidade de expansão da capacidade de investimento pode ser feita com a reserva de parte do produto excedente, que, não sendo utilizado para consumo, pode ser direcionado para a expansão da capacidade produtiva futura.

\footnotetext{
${ }^{5}$ Laura Beth Nielsen informa que os multimétodos quando contrapostos, possibilitam maior segurança na compreensão e análise dos dados.

${ }^{6}$ http://www.cvm.gov.br
} 
Entretanto, em países que adotaram o sistema de economia de mercado e com complexa organização socioeconômica, cuja produção é predominantemente realizada pela iniciativa de agentes econômicos privados, a ampliação da capacidade produtiva requer a compra de bens de capital. Esta opção exige capital disponível por parte dos investidores e, principalmente a confiança na razoável probabilidade de retorno monetário derivado dos investimentos realizados.

No Brasil, após uma fase de expansão econômica ocorrida no período 1967/74 com o chamado "Milagre" econômico, segundo o qual se pode perceber um crescimento produtivo médio correspondeu a 13\% (SARNO. 2006). Entre os anos de 1966 a 1969, constituiu-se numa primeira fase, denotando crescimento rápido do número de Sociedade Anônima de capital aberto que atingiu um total de 296, tendo nesse resultado grande participação os fundos- $157^{7}$ que atuaram praticamente como única fonte de recursos novos no mercado primário.

Diante de grande euforia com os resultados econômicos registrados até então, associado a elevação dos lucros, proporcionou o sentimento de que o mercado de capitais, por si só, seria capaz de proporcionar ótimos resultados financeiros a qualquer pessoa que nele aplicasse seus recursos.

Assim, a partir de 1970 um grande número de investidores individuais deu ensejo a um crescimento desproporcional dos preços das ações e, com ela a inevitável queda posterior das cotações, a partir do segundo semestre, quando essas expectativas revelaram-se demasiadamente otimistas, conformando, a partir de então, um quadro de crise e de estagnação do volume de negócios.

A recuperação somente vai ocorrer em 1976, com a expansão do nível de atividade econômica, resultante de um novo ciclo de crescimento econômico, que, no entanto, revelou-se bem menos sólido que o ciclo de crescimento anterior.

${ }^{7}$ O Fundo 157 foi criado pelo Decreto Lei $n^{\circ} 157 / 67$ e era uma opção dada aos contribuintes de utilizar parte do imposto devido quando da Declaração do Imposto de Renda para adquirir títulos emitidos por empresas nacionais que atendessem a determinados requisitos estabelecidos na legislação: http://www.cvm.gov.br/menu/consultas/fundos/fundos.html acesso em 26/11/2015. 
Diante de tal cenário econômico, pode-se destacar os esforços empreendidos pelo governo à época, no sentido de criar um órgão regulador específico e especializado para o mercado de títulos e valores mobiliários. Seguindo o desenho institucional implementado para o regulador do mercado de capitais nos Estados Unidos, dessa forma e mediante a Lei no 6.385, de 07.12.76, criou-se a Comissão de Valores Mobiliários. Partiu-se da premissa de que o Banco Central não estava sendo capaz de abraçar, na dimensão necessária, a tarefa de regulador do mercado de capitais e que, por outro lado, um órgão especializado estaria mais preparado para vencer os desafios que se colocavam (FILHO e PEDREIRA, 1992).

A recuperação somente vai ocorrer em 1976, com a expansão do nível de atividade econômica, resultante de um novo ciclo de crescimento econômico, que, no entanto, revelou-se bem menos sólido que o ciclo de crescimento anterior.

Diante de tal cenário econômico, pode-se destacar os esforços empreendidos pelo governo à época, no sentido de criar um órgão regulador específico e especializado para o mercado de títulos e valores mobiliários. Seguindo o desenho institucional implementado para o regulador do mercado de capitais nos Estados Unidos, dessa forma e mediante a Lei no 6.385, de 07.12.76, criou-se a Comissão de Valores Mobiliários. Partiu-se da premissa de que o Banco Central não estava sendo capaz de abraçar, na dimensão necessária, a tarefa de regulador do mercado de capitais e que, por outro lado, um órgão especializado estaria mais preparado para vencer os desafios que se colocavam (FILHO e PEDREIRA, 1992).

O objetivo principal desse artigo consiste em examinar como a CVM exerce suas funções no Estado do Rio de Janeiro.

\section{FATOS RELEVANTES E DEVER DE DIVULGAÇÃO}

Alguns teóricos da atividade econômica sustentam que um mercado é eficiente quando o preço de suas ações exterioriza todas as informações disponíveis sobre as empresas cujos títulos são negociados (FAMA, 1970).

Assim, levando em consideração o conceito de eficiência de Pareto, utilizado nas análises de equilíbrio geral para o caso do mercado de bens, passou-se a definir que o sistema em equilíbrio apresenta uma tendência de preços que permite o equilíbrio da oferta e a demanda de bens e maximiza o bem estar social, de forma que neste ponto não será possível melhorar o bem estar de uma pessoa sem que se reduza o bem estar de outra.

Entretanto, no mercado de capitais, diante de recursos escassos, o que limita a obtenção 
do máximo de resultados (função-utilidade) não são fatores de produção (como no mercado produtivo de bens), mas sim o acesso à informação a respeito das condições de retorno monetário e riscos aceitáveis no momento de tomada de decisão. Assim, o equivalente da alocação ótima de recursos que define a eficiência de Pareto no mercado de bens é a utilização 'plena e correta' da informação disponível no mercado de capitais (HERMANN, 2002).

A condição estará mais bem preservada se a informação relevante estiver disponível para todos os participantes do mercado e, ao mesmo tempo, se os preços dos valores mobiliários refletirem de forma rápida e correta todas as informações disponíveis.

Assim, a racionalidade dos investidores permite valorar a qualidade dos títulos, ou seja, refletir seus fundamentos, ajustando as características dos riscos.

Ocorre que, muitas críticas foram apresentadas pela teoria das finanças comportamentais e pelas escolas neo-keynesiana e pós-keynesiana, dentre elas é possível citar as hipótese de: comportamento (ir)racional, (in)eficiência das operações de arbitragem, ausência de custo de transação, ausência de custo de informação, ausência de (in)certeza.

Não é meu propósito aqui, destrinchar cada uma dessas críticas, pois envolveria outro tipo de pesquisa com outros objetos e objetivos. Entretanto, devo salientar que os agentes podem agir de maneira irracional e obter lucro, os arbitradores podem agir de forma limitada, as informações disponíveis ao mercado podem se revelar assimétricas, incompletas e precárias, sendo suscetíveis a especulações de curto prazo e a um processo de interpretação pelo investidor, que leva em consideração a sua expectativa acerca da avaliação dos demais agentes (NASH, 1950). Sob essas circunstâncias, a hipótese de mercados eficientes não se sustenta. Não se sustenta para os mercados produtivos (GODELIER, 1969) e nem no mercado de capitais (SHLEIFER, A. 2000).

Isto porque as informações relevantes não se refletem de forma plena nos preços, seja porque nem todas as informações estão disponíveis a todos e, quando são disponibilizadas, os agentes não as utilizam da mesma forma, seja porque nem todos percebem os possíveis impactos de uma informação, seja porque são incompletas ou insuficientes, indistintamente a todos.

Diante do consenso da teoria econômica acerca da inexistência de eficiência natural do mercado de capitais é que surgiu a necessidade de se estabelecer a tentativa de controle da divulgação dos fatos relevantes da Sociedade Anônima de capital aberto por meio da CVM sob pena de incidência no crime de uso indevido de informação privilegiada (insider trading). ${ }^{8}$ Entretanto, não são objeto deste estudo os comportamentos e infrações a 
dispositivos legais que tratam da vedação à negociação com base em informação privilegiada (insider trading).

Dedicamo-nos apenas a explicitar como a CVM lida com os agentes de mercado e qual o alcance do dever divulgação de fatos relevantes, com o objetivo de tentar perceber o grau de insegurança no cumprimento e aplicação das normas sobre a matéria.

No âmbito das sociedades anônimas, o dever de informar (disclosure) atribuído aos administradores da companhia, no qual se inclui o dever divulgação de fatos relevantes, identifica-se como alicerce fundamental da regulação do mercado de capitais. $\mathrm{O}$ ordenamento jurídico brasileiro prevê expressamente a obrigação de divulgação de fatos relevantes desde 1976, quando a Lei 6404/76 foi promulgada e estabeleceu que os administradores de companhias abertas são obrigados a divulgar qualquer deliberação da assembleia geral ou dos órgãos da administração, ou fato relevante ocorrido nos negócios da companhia que possa influir, de modo ponderável, na decisão dos investidores de comprar ou vender valores mobiliários.

O tema desperta especial interesse aos administradores das companhias, pois além da fiscalização realizada pela CVM, a eventual violação desta obrigação é considerada infração grave e pode resultar até em aplicação de pena de inabilitação para o exercício do cargo de administrador de qualquer outra companhia aberta. ${ }^{9}$

Afirma-se que o dever de informação tem por objetivo garantir que todos os dados importantes para o processo de precificação dos valores mobiliários de uma companhia aberta sejam disponibilizados de forma ampla, simultânea e equitativa a todos os agentes de mercado, contribuindo para o melhor desempenho possível do mercado de capitais e corrigindo eventuais falhas resultantes de situações de assimetria de informação (EIZIRICK, 2011). Assim, o propósito de se estudar e identificar o comportamento da CVM acerca do dever de divulgação de fatos relevantes é mais abrangente do que simplesmente prevenir a prática de insider trading e, sua violação enseja punição mesmo que não tenha sido constatada tal prática de insider trading.

\footnotetext{
${ }^{8}$ Uso Indevido de Informação Privilegiada - Lei 6385/76 - Art. 27-D. Utilizar informação relevante ainda não divulgada a mercado, de que tenha conhecimento e da qual deva manter sigilo, capaz de propiciar, para si ou para outrem, vantagem indevida, mediante negociação, em nome próprio ou de terceiro, com valores mobiliários: Pena - reclusão, de 1 (um) a 5 (cinco) anos, e multa de até 3 (três) vezes o montante da vantagem ilícita obtida em decorrência do crime.
}

${ }^{9}$ Art. 18 da Instrução CVM 358 c/c $§ 3^{\circ}$ do art. 11 da Lei 6.385/1976. 


\section{A FORMA DE ATUAÇÃO E AS REPRESENTAÇÕES DOS SERVIDORES DA CVM}

Embora seja possível fazer um estudo acerca da jurisprudência da CVM acerca das decisões existente nos processos administrativos sancionadores (PAS) (PINTO RIOS, BOECHEM, 2014) pudemos perceber que alguns julgadores, antes mesmo de iniciar as sessões de julgamento, já tinham muitos aspectos das questões a serem debatidas, praticamente prontas na cabeça, independentemente do que dispunha a lei. Chegavam com suas decisões prontas e seu conteúdo construído com base em concepções advindas de percepções próprias acerca da "eficiência do funcionamento do mercado" e das formas de atuação de uma Sociedade Anônima de capital aberto ou de seus administradores.

Assim, em análise da presença de fatos ainda não considerados definitivos, ouvimos de um dos julgadores que "a informação deve ser fornecida ao mercado quando se torna uma pretensão concreta internamente acerca de um contrato ou negócio. Se o negócio vai ser fechado ou não, isso não importa". Entretanto, quando perguntado quem seria o "tal mercado" e sobre quando se poderia identificar uma "pretensão concreta", ele disse que: "é muito difícil para quem está de fora saber ou para nós julgarmos sem provas".

Em outra situação de percepção se um fato seria relevante em razão de ser ou considerado definitivo pudemos perceber pelo debate ocorrido em sessão que "o fato é relevante quando passa ser uma possibilidade real de um negócio se concretizar, ressaltando-se a incerteza de sua ocorrência" (...).

Em outra abordagem, um dos julgadores, em razão da identificação de um fato poder ter divulgação paulatina, conforme os acontecimentos internos, obtive a seguinte referencia: "A mera intenção de se adquirir outra companhia é um fato relevante para o mercado, porém a mera conjectura fica no campo da especulação". Indaguei acerca dos interesses dos acionistas da sociedade empresária a ser incorporada poderiam sofrer abalo significativo e, a mesma pessoa me que:

a função não é só proteger os acionistas, que no Brasil são quase todos profissionais, mas sim proteger o mercado". (...) "Assim, se existissem negociações para aquisição de uma concorrente, deve-se divulgar a negociação, mas se era apenas uma conjectura, uma um ou outro comentário dentro da diretora, não, não é caso de divulgação paulatina, pois nem fato existiria ainda.

Todos esses relatos foram extraídos em processo em que os administradores foram absolvidos da sanção de não divulgação de fatos relevantes ao mercado. Não fizemos uma pesquisa quantitativa acerca dos números de sanções aplicadas pela CVM no período que lá estive, mas tivemos notícias de que o órgão colegiado aplica sanções aos administradores na maioria dos 
casos julgados. Entretanto, o que tais relatos me levam a considerar é a forma de raciocínio que se valem os servidores que atuam no órgão colegiado de julgamento da Comissão de Valores Mobiliários (CVM).

É possível perceber uma forte tradição burocrática no sentido de ver o Estado, ali representado pela CVM, com órgão protetor do mercado, ainda que muitos servidores tenham formação acadêmica especializada e com bastante atuação no mercado de capitais brasileiro e com conhecimento das formas de atuação de outras agências de regulatórias internacionais.

Tais práticas refletem as tradições dos demais órgãos burocráticos brasileiros, mesmo em um órgão que lida com as práticas de agentes econômicos com atuação e práticas internacionais.

\section{AS BUROCRACIAS E SEUS PRESSUPOSTOS TEÓRICOS}

Há muito tempo que se tem se percebido que as burocracias, como instituições sociais, tornaram-se fatores relevantes no acesso de diversos grupos sociais ao exercício dos direitos tipificados em leis formalmente produzidas. Através da burocracia é que normalmente se pretendem atingir metas previamente estabelecidas. Entretanto, ordinariamente percebe-se que tais organizações são tidas como obstáculos aos resultados positivos ao idealizado em planejamentos teóricos.

Essa contradição também pode ser percebida na análise de certos estudos sociológicos e na percepção de discursos políticos, seja de administradores de políticas públicas ou mesmos por pessoas comuns que lidam com a burocracia como forma de organização da atividade governamental.

No estudo de qualquer burocracia deve-se inicialmente evitar alguns dos principais problemas ou dilemas teóricos. No Brasil a história registra longo período histórico de repressão política ao exercício da cidadania. As organizações burocráticas são ordinariamente chamadas a fornecer meios instrumentais para a execução de medidas voltadas a superar baixíssimos índices de desenvolvimento humano relacionado ao exercício da cidadania. Assim, os órgão burocráticos são chamados à dinamizar as pretensões públicas consolidadas em termos legais. Sob certo aspecto, a teoria sociológica clássica sobre burocracia, pode ser identificada na obra: O Fenômeno Burocrático, de Michel Crozier, que dispõe os "aspectos disfuncionais da organização moderna", partindo-se da premissa de que nas burocracias periférica, não haveria as características básicas correspondentes às burocracias complexas dos países tidos como modelos ideais normalmente identificados na Europa ocidental, que já teriam atingido o maior grau de desenvolvimento socioeconômico e que, em outros locais, a resistência do fator humano, movido por força de seus próprios interesses e estratégias são caracterizados como "ciclos de fases de burocratização que passam por acidentes de sucessão" (CROZIER, 1963). 
Sob certo aspecto o referido dilema acerca da teoria da burocracia lida com moldes de racionalidade, de impessoalidade, de saber e competência técnica estereotipada (AMORIM, 1975).

A dificuldade mencionada pode ser identificada na interpretação estereotipada na noção de burocracia retirada de Max Weber (WEBER, 1999). Em função deste fato é que parte da teoria acerca da burocracia não consegue estabelecer critérios comuns comparativos que possam ser seguros suficientes a fim de dar conta das diversas formas de burocracia encontradas nas diversas formas de convivência humanas.

Fundamentalmente, em razão da referida dificuldade, é que se busca neste trabalho dar maior importância nas evidências encontradas no campo estudado a fim de superar o dilema de se entender a burocracia atuante na CVM como "disfuncionais", o que tal estereótipo serve muito mais para questionar a própria teoria do modelo burocrático puro, que nem o próprio Max Weber concebeu como de existência possível (WEBER, 1972). Aceitar as imperfeições das burocracias estranhas ao mundo europeu ocidental como "disfunções" quando colocadas à comparação do modelo ideal clássico de burocracia weberiana tida como "funcional" acarreta, ao meu ver em certa racionalidade histórica preconcebida (AMORIM, 1975).

Estudos clássicos no campo da antropologia acerca de burocracias que não se influenciaram diretamente com a racionalidade clássica europeia apresentaram vantagens epistemológicas e permitiram a identificação de um tipo de racionalidade não comprometida com princípios organizadores do comportamento nas sociedades ocidentais assim como permitem evidenciar a dificuldade de se operar com lógicas e racionalidades originárias e em voga em outras regiões (FALLERS, 1956).

O desenvolvimento antropológico das pesquisas envolvendo o comportamento das referidas organizações proporciona ao pesquisador apreender a razão social explicitada nos diferentes arranjos das relações humanas através da identificação de códigos sociais diferentes de uma matriz definida a priori o que proporciona a apreensão mais exata do objeto de estudo e o aprendizado das sociedades que estuda por meio da convivência com seu objeto de pesquisa que permite entender e explicar as organizações sociais.

Neste sentido Clifford Geertz (GEERTZ, 1989) afirma que:

ideias e crenças podem ser relacionadas com a realidade em uma dupla forma: com os fatos da realidade ou com os anseios que essa realidade, ou a reação a essa realidade, faz surgirem. Onde existe a primeira conexão, descobrimos um pensamento que em princípio é verdadeiro; onde aparece a última relação, enfrentamos ideias que só podem ser verdadeiras por acidente e que são passíveis de estarem viciadas por preconceitos, sendo esta palavra tomada em sua acepção mais ampla. $\mathrm{O}$ primeiro tipo de pensamento merece ser chamado de teórico, enquanto que o último deve ser 
caracterizado como parateórico. Talvez se possa também descrever o primeiro como racional e o último como afetado emocionalmente - o primeiro como puramente cognitivo e o segundo como estimativo. Tomando emprestado um símile de Theodor Geiger o pensamento determinado pelo fato social é como uma torrente pura, cristalina, transparente; as ideias ideológicas, como um rio sujo, lamacento e poluído pelas impurezas que nele se acumularam. É saudável beber no primeiro; o outro é um veneno que deve ser evitado.

Desse modo a perspectiva antropológica oferece afiados argumentos no sentido de questionar inclinações etnocentristas à teoria das organizações sociais tendo em vista que lida com uma racionalidade em confecção para compreender os sistemas que estuda (AMORIM, 1975).

Ao se partir dessa perspectiva antropológica é possível perceber que a análise das burocracias enfrenta sério impasse no sentido de que ao se utilizar da racionalidade exógena em termos comparativos preconcebe referências estranhas ao campo estudado e tende a apontar "ineficiências", "defeitos", "vícios" ou "disfunções" em realidade que podem não compartilhar a mesma racionalidade do tipo ideal definido a priori.

Diante de tais assertivas é que se faz necessário uma leitura cuidadosa da literatura clássica, especialmente quanto às interpretações e usos concedidos ao pensamento de Max Weber de modo a permitir menor rigidez e maior validade à teoria da burocracia. (AMORIM, 1975).

As concepções aqui adotadas se aproximam da teoria burocrática inspirada em Max Weber, mas utilizando-a com vistas na realidade empírica observada, ou seja, procuramos utilizar as ideias de Max Weber de modo como melhor se ajustaram à pesquisa sem a pretensão de testar a validade da tipologia formulada.

Entretanto, o referido contraste pressupõe o destaque dos principais aspectos da referida teoria de Max Weber, mas em conexão com outros pontos chave existentes em sua própria teoria.

Burocracia e burocratização recebe de Max Weber uma ideia mais abrangente no sentido de autoridade ou dominação que, em sentido mais amplo, estão relacionados aos elementos mais importantes da ação social, sem significar que esta implique em sempre e sempre em dominação. A autoridade ou dominação, na obra do autor, encontra-se vinculada às noções de legitimidade e de ordem e, no sentido aqui emprestado, uma organização burocrática tem sua estrutura de autoridade socialmente legitimada dentro da ordem social onde se encontra incluída (WEBER, 1972).

A concepção de ordem estatuída descrita por Max Weber faz expressa referência a duas grandes ordens institucionais globais que são o feudalismo e o capitalismo que permitiram a ele perceber de forma mais global a perspectiva histórica do mundo moderno europeu do início do século XX, mas que não esgota a ideia de burocracia vista de ângulos históricos diferentes, tal como, por exemplo, percebido no Brasil em pleno século XXI (WEBER, 1972). O feudalismo é identificado na obra de Max Weber como referência ou exemplo limite em 
face do tipo ideal da ordem tradicional que abrange a autoridade patriarcal que antecede historicamente a autoridade patrimonial. Este aspecto descrito por Max Weber faz alusão ao fato de que o feudalismo poderia enveredar para uma vertente patrimonialista ou pender para uma vertente patriarcal, tendo em vista os rompimentos dos vínculos ocorridos entre o senhor e as pessoas a ele vinculadas por dependência que, por sua vez, geraram modos específicos de organização social e de organização burocrática (WEBER, 1972).

A estrutura de uma dominação recebe seu caráter sociológico da natureza geral da relação entre o senhor ou os senhores e seu aparato, e entre estes dois e os dominados, e, além disso, de seus princípios específicos de organização, isto é, distribuição de poderes de mando.

Por "senhor" Max Weber identifica o líder cujo poder de mando pretendido e de fato exercido não lhe foi delegado por outro líder, assim como identifica "aparato" como as pessoas que na forma mencionada se põem a disposição especial do senhor (WEBER, 1972, p. 197).

Maria Stella Faria de Amorim destaca que a possibilidade de diversas inclinações no modo de organização social foi seguida paralelamente pela adoção de modos de quadros administrativos com características próprias, somente compreensíveis se relacionadas às condições históricas anteriores as quais estavam relacionadas. Assim, afirma ela, Max Weber utiliza de forma coerente um enfoque sistemático sobre rupturas ocorridas na relação de dominação entre os agentes e entre estes e a ordem que os envolve (AMORIM, 1975).

Levando em consideração a perspectiva histórica de Max Weber utilizamo-nos da incorporação do conceito de ordem autoritária contida na obra de Maria Stella Faria de Amorim que a usa como categoria analítica mais abrangente e que permite compreender os princípios reguladores da hierarquia de autoridade nas burocracias, tendo em vista que, nas palavras da autora, "esta mesma ordem se configura em significados simbólicos mentalizados pelos agentes" (AMORIM, 1975).

Em sentido semelhante, utilizado por Simon Schwartzman, procuro demonstrar que o Brasil herdou um sistema político que não funciona como "representante" ou "agente" de grupos, castas ou classes sociais determinados, mas que tem uma dinâmica própria e independente, que só pode ser entendida se examinarmos a história da formação do Estado brasileiro (SCHWARTZMAN, 1988).

Esta concepção parece incompreensível dentro de uma visão de corte marxista ou economicista convencional que tende a interpretar tudo o que ocorre em uma sociedade em termos de sua divisão de classes, mas torna-se mais inteligível se aproximada de uma perspectiva weberiana, que distingue e trata de maneira diferenciada os sistemas de classe, os sistemas de dominação política e os sistemas de privilégio social e status em uma sociedade. É pela aproximação à perspectiva weberiana que se pode perceber que o Estado brasileiro tem 
como característica histórica predominante sua dimensão que Simon Schwartzman identifica como "neopatrimonial", que é uma forma de dominação política gerada no processo de transição para a modernidade com o passivo de uma burocracia administrativa pesada e uma "sociedade civil" (grupos sociais ou religiosos, étnicos, linguísticos, nobreza etc.) fraca e pouco articulada (SCHWARTZMAN, 1988).

Evitando a todo custo a utilização imediata ou pura das categorias de Max Weber ou a de utilizá-las com ênfase exagerada do contexto jurídico em detrimento das condições sociais tal qual faz, a nosso ver, Raymundo Faoro (FAORO, 2001) utilizamo-nos também da obra de Maria Sylvia de Carvalho Franco (FRANCO, 1974) em que prevalece a compreensão da herança histórica escravocrata como parte do sistema de relações sociais em cujo curso se procede à unificação dos diferentes e contraditórios elementos nele presentes. Nesta obra a autora aponta que uma das mais importantes implicações da escravidão foi o fato de que no Brasil,

uma formação sui generis de homens livres e expropriados que não foram integrados à produção mercantil e, a existência desse tipo humano, orientou a forma como se organizou a ocupação do solo (...) com a existência de homens destituídos da propriedade, mas não sem sua posse, e que não foram plenamente submetidos às pressões econômicas; homens livres e expropriados que não conheceram os rigores do trabalho forçado e não se proletarizaram. Formou-se, antes, uma "ralé" que cresceu e vagou ao longo de quatro séculos.

Esta abordagem permite também acentuar as peculiaridades das relações de dominação, descritas em Max Weber, principalmente, segundo a autora, quando a partir de 1840, no Brasil, foi-se consolidando um governo centralizador que, diante de uma grave crise econômica decorrente de comoções políticas europeias, e de forma a garantir o poder do governo, resolveu montar um aparelho administrativo que concentrasse realmente os meios pecuniários da administração e dispusesse de um corpo de agentes disciplinados para o exercício metódico e despersonalizado das funções públicas. Entretanto, segundo a autora, a tendência de burocratização do aparelho administrativo encontrava seus limites nas condições mesmas que a havia tornado uma necessidade, ou seja, o agente governamental que desempenhava suas atribuições funcionais, orientado por fortes interesses e influências que envolviam a sua vida de maneira imediata, do que por longínquos e abstratos controles legais (FRANCO, 1974). Os vínculos entre funcionário público e grupos sociais de que participava pesavam bem mais que as obrigações e lealdades assumidas com o governo, empregador distante e desmaterializado que se utilizava de um conjunto de fórmulas rudimentares que disciplinava a realização dos objetivos do Estado, mas de precária eficácia. Acrescenta ainda a autora que: "o comportamento do pessoal que integrava os quadros pouco se procedia por 
meio de regulamentos expressos; o pessoal regia-se, de fato, pelo que estava costumeiramente fixado, e não por regulamentos ou protocolos, na verdade inexistentes" (FRANCO, 1974).

\section{A PERSPECTIVA LOCAL}

Uma das principais diferenças entre as democracias europeias ocidentais e sociedades como a brasileira, cujas instituições políticas estão sujeitas a um processo constante de instabilidade, é a natureza distinta da formação do Estado e das relações deste com os demais setores da sociedade. Não se trata de diferenças de tipo cultural, nem imutáveis, mas de realidades que se originam de processos históricos bem distintos, que, por isso, conduziram a resultados também muito diferentes.

O Estado de hoje não é a mesma coisa do que o Estado do século XVIII descrito por Maquiavel ou Rousseau em suas clássicas obras de "O Príncipe” (MAQUIAVEL, 2008) e "Do Contrato Social" (ROUSSEAU, 2007), da mesma forma que o Estado brasileiro é profundamente distinto do Estado francês, inglês, norte americano ou soviético, exigindo-se não pautar conclusões com base em tradição de pensamento europeu e valer-se de uma perspectiva que tome em conta tais variações. O Estado passou a ser identificado como uma instituição específica dentro de um espaço geográfico, que não apenas executa funções de manutenção de fronteiras e de soberania, mas adotou perspectiva mais estrutural, isto é, o Estado é analisado como uma instituição ocupada por pessoas, o Estado é dotado de estrutura e processos que lhe são próprios.

Em face das noções de burocracia apresentadas corre-se o risco de assumir trágicas interpretações sociológicas e indevidas associações à realidade de sociedades, como a brasileira, cujo curso histórico se afasta do padrão clássico de florescimento europeu.

Ajustar a aplicação de "luta de classes" em sociedades cuja "estratificação econômica" não satisfaz às condições indicadas por Karl Marx (MARX, 2005), quanto à aquisição de consciência na situação do mercado capitalista, é tão irreal e insatisfatória quanto adotar a noção de burocracia de Max Weber no sentido de modelo racional-legal (WEBER, 1972). O uso de tais noções academicamente descontextualizadas mostra-se o caminho mais curto para equívocos metodológicos e não contribui como instrumento de reflexão acadêmica.

As referidas teorias não podem servir para a representação da realidade brasileira porque na base dessas teorias está à ideia de democracia. A teoria de burocracia do Max Weber está fundada na questão da legitimidade da lei e da regra como forma de governo. Max Weber escreveu para um mundo liberal, burguês ocidental e com toda a sua racionalidade liberal. 
Mas a relação dos investidores e do modo de agir dos servidores públicos da CVM, com atuação no Rio de Janeiro, com as nossas regras não estão fundadas em tais parâmetros. Na base da burocracia observada não se encontra parâmetros democráticos. A preocupação é com o "mercado", entidade abstrata que mal é percebida nas sessões de julgamento, mas referenciada nos argumentos jurídicos inseridos nas decisões.

\section{CONCLUSÃO}

Os dados até o presente momento coletados na pesquisa que ainda esta em curso, permite concluir que a CVM, é influenciada por critérios que refletem um ethos institucional, interno, com saberes e poderes locais (GEERTZ, 1999), que acabam elegendo as situações consideradas problemáticas para o mercado, bem como os métodos de solução dos conflitos relativos à noção de insegurança do mercado.

Pelos dados obtidos nesta pesquisa percebemos que a própria formação do Estado e da burocracia brasileira não teve base teórica e nem se origina, representa-se ou se volta em favor do cidadão-investidor, mas sim ela se representa em favor do Estado, nesta pesquisa representada pela atuação da CVM. O aparato burocrático jamais suplantou a natureza fortemente paternalista da sociedade ibérica e, pelas práticas observadas persiste até hoje.

É possível perceber também a presença de forte tradição burocrática no sentido de ver o Estado, ali representado pela CVM, com órgão protetor do mercado, categoria presente em quase todos os servidores que tive contato, mas que não se relaciona com os investidores capitalistas que, pelo menos teoricamente pretender obter sucesso monetário e financeiro, através do sucesso de empreendimento das sociedades empresárias com atuação no mercado brasileiro. Assim, mesmo que muitos servidores tenham formação acadêmica especializada e com bastante atuação no mercado de capitais brasileiro e com conhecimento das formas de atuação de outras agências de regulatórias internacionais, é possível perceber que é a CVM quem deve controlar o mercado para que ele seja efetivamente "eficiente", em um comportamento em que o "mercado" é a causa e o destinatário de toda e qualquer atuação e a CVM exerce a sua tutela. 


\section{REFERÊNCIAS}

AMORIM, M. S. (1975). Homens Burocráticos. Sociologia das Organizações Públicas do Nordeste Brasileiro. Rio de Janeiro.

BOECHEM, Felipe Tavares; PINTO RIOS, Alexandre Carvalho. 2014. Análise da Jurisprudência da CVM sobre o Dever de Divulgação de Fatos Relevantes. Revista de Direito Empresarial, vol. 5/2014.

CROZIER, M. (1981). O Fenômeno Burocrático: ensaio sobre as tendências burocráticas dos sistemas de organização modernos e suas relações, na França, com o sistema social e cultural. (J. A. Sobrinho, Trad.) Brasília: Universidade de Brasília.

EIZIRICK, Nelson et ali. (2011). Mercado de capitais - Regime jurídico. Rio de Janeiro: Renovar.

FALLERS, L. (1956). Bantu bureaucracy: a century of political evolution among the Basoga of Uganda. Uganda.

FAMA, Eugene F. Efficient Capital Markets: A Review of Theory and Empirical Work. Source: The Journal of Finance. (May, 1970). Vol. 25, No. 2, Papers and Proceedings of the Twenty-Eighth Annual Meeting of the American Finance Association New York, N.Y. December, 28-30, 1969.

FAORO, R. (2001). Os Donos do Poder. Formação do Patronato Político Brasileiro (3 ed.). São Paulo: Globo.

FRAGA, Arminio; GOLDFAJN, llan; MINELLA, Andre. (2004). Inflation Targeting in Emerging Market Economie. The MIT Press: NBER Macroeconomics Annual 2003, Volume 18.

FRANCO, M. S. (1974). Homens Livres na Ordem Escravocrata $\left(2^{\mathrm{a}}-2^{\mathrm{a}}\right.$ reimpressão ed.). São Paulo: Ática.

GEERTZ, C. (1989, a). A Interpretação das Culturas. Rio de Janeiro, RJ, Brasil: LTC Livros Técnicos e Científicos.

GEERTZ, C. (1997). O saber local. Novos ensaios em antropologia interpretativa. (V. M. Joscelyne, Trad.) Petrópolis: Vozes.

GODELIER, Maurice. (1969). Racionalidade e irracionalidade na Economia. Biblioteca Tempo Brasileiro. Rio de Janeiro. 
HERMANN, J. (2002). "Financial Structure and Financing Models: The Brazilian, Experience over the 1964-1997 Period”, Journal of Latin American Studies, no 34.

KOGUT, Bruce; WALKER, Gordon. (2001). The small world of firm ownwership and acquisitions in germany from 1993 to 1197: the durability of national network. Americam Sociological Review, v. 66, $\mathrm{n}^{\circ} .03$.

LAMY FILHO E BULHÕES PEDREIRA (1992). A Lei das S.A., editora Renovar, Rio de Janeiro.

LAZZARINI, Sérgio G. (2011). Capitalismo de Laços. Os donos do Brasil e suas conexões. $3^{\mathrm{a}}$ edição. Rio de Janeiro. Elsevier Editora.

MALINOWSK, Bonislaw. (1922). Argonauts of the Western Pacific. Nova York: E. P. Dutton.

MAQUIAVEL, N. (2008). O príncipe. São Paulo: DPL.

MARX, K. (2005). Crítica da Filosofia do Direito de Hegel. (R. E. Deus, Trad.) São Paulo: Boitempo.

NASH, John F., Jr. (1950). Equilibrium points in “n”-person games. Proc. Nat. Acad. Sci. U. S. A. 36, p. 48-49.

PINTO RIOS, Alexandre Carvalho; BOECHEM, Felipe Tavares. (2014). Análise da Jurisprudência da CVM sobre o dever de divulgação de fatos relevantes. Revista de Direito Empresarial. vol. 5/2014, p. 123.

ROUSSEAU, J. J. (2007). Do Contrato Social. São Paulo: Martin Claret.

SARNO, Paula Marina. (2006). A Criação da CVM e a Regulação do Mercado de Capitais no Brasil - 1976/1986. Dissertação de Mestrado em Economia na Universidade Federal do Rio de Janeiro.

SCHWARTZMAN, S. (1988). BASES DO AUTORITARISMO BRASILEIRO (3 ed.). Rio de Janeiro: Campus.

SHLEIFER, A. (2000). Inneficient Markets, An Introduction to Behavioral Finance. Oxford University Press, New York.

WEBER, M. (1972). Economia e Sociedade: fundamentos da sociologia compreensiva

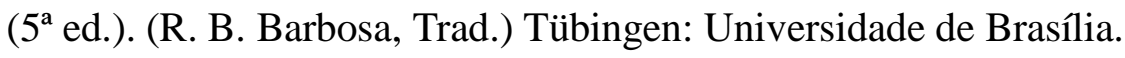

WEBER, M. (1999). A Ética Protestante e o Espírito do Capitalismo. (14 ed.). São Paulo: Pioneira. 